\title{
The impact of naphthalimide derivative on the mitigation of mild steel corrosion in sulfamic acid medium: experimental and theoretical insights
}

\author{
Yash Bhatt $^{1} \cdot$ Preethi Kumari $^{1}$ (D) $\cdot$ Dhanya Sunil $^{1} \cdot$ Suma A. Rao ${ }^{1} \cdot$ Prakasha Shetty $^{1} \cdot$ Sneha Kagatikar $^{1}$
}

Received: 11 December 2020 / Accepted: 15 March 2021 / Published online: 2 April 2021

(c) The Author(s) 2021

\begin{abstract}
The deterioration of iron-based alloys, especially mild steel (MS) is one amongst the most challenging problems faced in various chemical industries. The present work focuses on the potential activity of a naphthalimide derivative namely 2-(2-hydroxyethyl)benzo[de]isoquinoline-1,3-dione (HBIQ) as corrosion inhibitor for MS in sulfamic acid (SA) medium in the temperature range from 303 to $323 \mathrm{~K}$. Potentiodynamic polarization (PP) and electrochemical impedance spectroscopy (EIS) were employed in the experimental measurement and HBIQ exhibited $89 \%$ inhibition at its optimum concentration. HBIQ demonstrated electrostatic interactions with MS surface and behaved as a mixed type of inhibitor by obeying Langmuir's isotherm model. Surface characterization of uninhibited and inhibited MS specimens combined with elemental analysis data provided clear evidences for the formation of a protective adsorption layer of HBIQ on MS surface. Spectral analysis such as Ultraviolet visible and Fourier Transform Infra-red spectral analyses were carried out in order to confirm the adsorption of HBIQ on to the metal surface. The density functional theory calculations supported the experimental results and indicated the contribution of delocalized $\pi$-electrons in the naphthalimide unit and the lone-pair electrons of oxygen in the carbonyl and hydroxyl group for improved adsorption of HBIQ onto MS surface, thereby reducing the corrosion of the alloy in SA environment.
\end{abstract}

Preethi Kumari

preethi.prabhu@manipal.edu

1 Department of Chemistry, Manipal Institute of Technology, Manipal Academy of Higher Education, Manipal 576104, India 


\section{Graphic abstract}

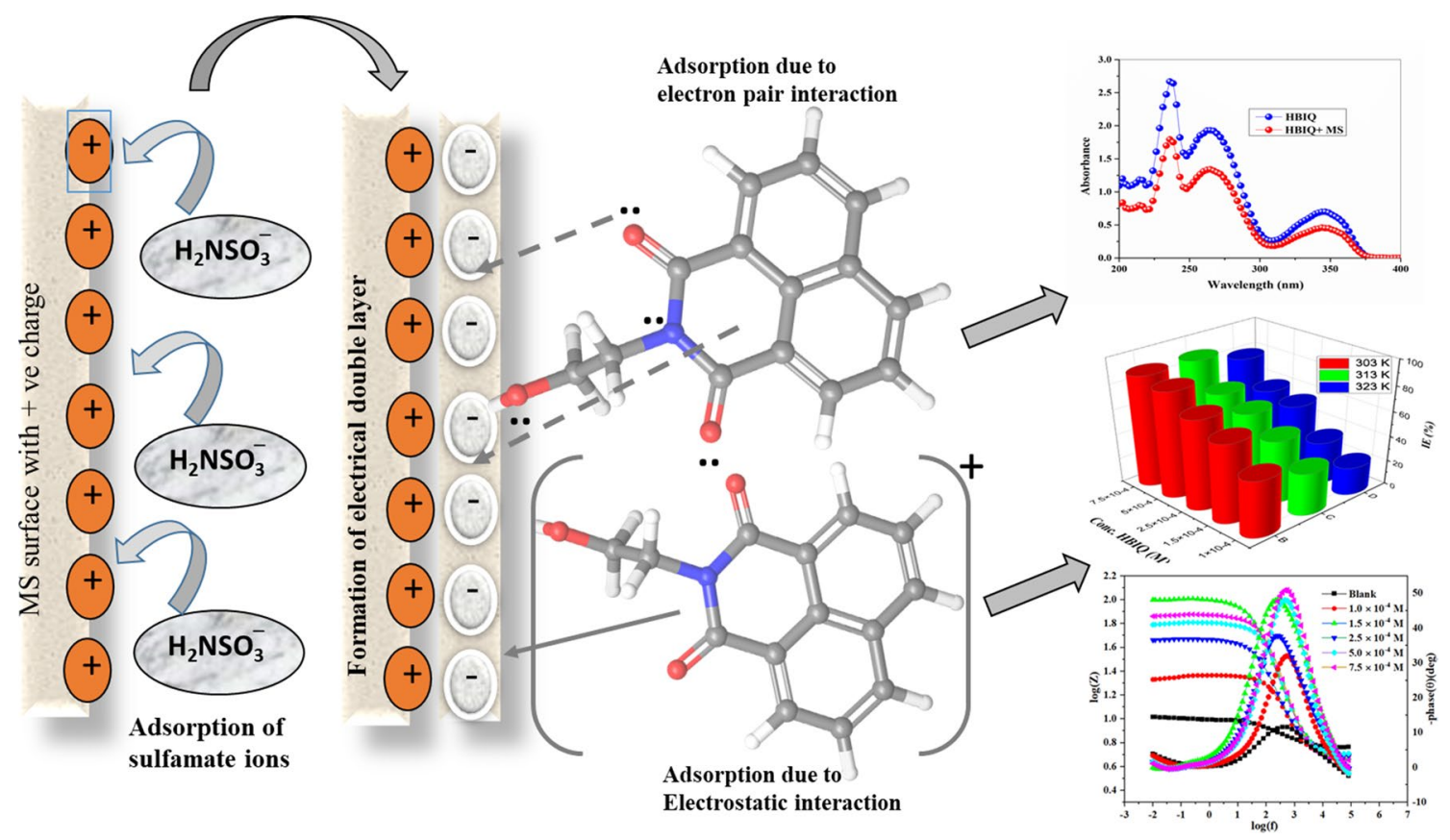

Keywords Sulfamic acid $\cdot$ Impedance $\cdot$ Physisorption $\cdot$ Polarization $\cdot$ DFT $\cdot$ Naphthalimide

\section{List of symbols}

IE Inhibition efficiency (\%)

CR Corrosion rate (mmpy)

$i_{\text {corr }} \quad$ Corrosion current density $\left(\mathrm{mA} \mathrm{cm}^{-2}\right)$

$E_{\text {corr }} \quad$ Corrosion potential (V/SCE)

$\beta_{\mathrm{c}} \quad$ Cathodic slope $\left(\mathrm{mV} \mathrm{dec}^{-1}\right)$

$T \quad$ Temperature (K)

$\beta_{\mathrm{a}} \quad$ Anodic slope $\left(\mathrm{mV} \mathrm{dec}{ }^{-1}\right)$

$E_{\mathrm{a}} \quad$ Energy of activation $(\mathrm{kJ} / \mathrm{mol})$

$\Delta \mathrm{H}^{\#} \quad$ Enthalpy of activation $(\mathrm{kJ} / \mathrm{mol})$

$\Delta \mathrm{S}^{\#} \quad$ Entropy of activation $\left(\mathrm{J} \mathrm{mol}^{-1} \mathrm{~K}^{-1}\right)$

$R_{\mathrm{ct}} \quad$ Charge transfer resistance $\left(\mathrm{ohm} \mathrm{\textrm {cm } ^ { 2 } )}\right.$

$C_{\mathrm{dl}} \quad$ Double layer capacitance $\left(\mu \mathrm{F} \mathrm{cm}^{-2}\right)$

$\Delta G_{\text {ads }}^{\circ}$ Change in free energy $\left(\mathrm{KJ} \mathrm{mol}^{-1}\right.$

\section{Introduction}

Among the iron-based alloys, mild steel (MS) has drawn significant attention due to not only its higher mechanical strength, ductility, machinability and weldability compared to other alloys, but also easy availability and exceptionally low cost (Ahmed et al. 2019). Wide usage of MS is observed in various construction systems, gas storage tanks, pipelines for oil and gas distribution, heat exchangers, boilers and engineering machineries (Shukla and Ebenso 2011).
However, the alloy can undergo electrochemical oxidation on interaction with the environment resulting in adverse effects on its properties, which can later weaken the equipment. Hence, protection of MS and thereby conservation of economic resources in technology has gained wide attention. In most of the chemical industries, the deposition of scale on the metal surface of heat exchangers, evaporators and boilers, considerably reduces the rate of heat transfer, lowering the efficiency of the equipment. Thus, in order to ensure and maintain trouble-free functioning of these plants, descaling is essential. Different acid solutions are largely employed for the removal of unwanted scale and deposits from the metal surface, which causes metal dissolution. The destruction of MS in acid environment needs to be addressed as huge amount of material loss occurs due to acid wash every year worldwide.

Among the commercially available acids, Sulfamic acid (SA) or mono amido sulfuric acid $\left(\mathrm{H}_{2} \mathrm{NSO}_{3} \mathrm{H}\right)$ is one of the most frequently used acid for pickling, cleaning and descaling process (Fouda and Ibrahim 2018; Morad 2008). Though SA is a stable solid compound, it can easily undergo hydrolysis in aqueous solutions resulting in the formation of sulfamate of ammonium and ammonium hydrogen sulfate (Motamedi et al. 2014). The SA features many attractive properties including non-volatile, non-hygroscopic, odorless, stable and ability to act as strong acid in aqueous 
solution with significantly less corrosion to the metals exposed. These unique characteristics allow its usage in many chemical industries for dissolving hard iron oxide and variety of water-formed scales and deposits from the metal surface without any causing any chloride-induced stress corrosion cracking (SCC) (Fouda et al. 2014). It is widely used as a cleaning agent in a variety of industrial applications including cooling tower systems, desalination plants, heat exchangers and flash evaporators. Moreover, SA is extensively used in sugar industry for scale removal, because it is non-toxic and easily solubilizes hard scales without promoting pitting corrosion. But, tremendous metal loss occurs during such descaling processes (Motamedi et al. 2013). Hence, the addition of corrosion inhibitors to the corrosive medium is one of the most effective means to combat MS corrosion and thereby conserve the alloy.

The ability of an organic molecule to inhibit the metal deterioration mainly depends on its structural framework, the interaction with the metal surface, the mode of adsorption and the corrosive medium. Moreover, there are various conditions that aid in the selection of a suitable inhibitor substance including the cost and amount of the inhibitor required, ability to treat the corroded surfaces, stability in the environments and long-term toxicological effects on the environment. Though there are numerous organic molecules reported as potential inhibitors for MS, to the best of our knowledge, there are no literature evidences on heterocyclic 1,8-naphthalimide derivatives investigated for their potential to mitigate MS corrosion. Naphthalamides are one of the important classes of polycyclic imides consisting of a flat structure with hetero aromatic system. The widespread biological applications of naphthalimide and their derivative products including antitumor activity against both murine and human tumor cells (kamal et al. 2002) antitrypanosomal (Muth et al. 2007) antiviral (Clark et al. 1993), local anesthetics (Berque-Bestel et al. 2003), analgesic (Duke et al. 2010) and many more makes them potential class of organic compounds. Furthermore, naphthalimide derivatives have also been used as optical brighteners (Dorlars et al. 1975), sensors (Wolfbeis 2005), fluorescent probes (Xu et al. 2010), etc.

There are only a few reports available on the use of corrosion inhibitors for MS in SA medium (Fouda and Ibrahim 2018; Morad 2008; Fouda et al.2014; Motamedi et al. 2011; Motamedi et al. 2013, Motamedi et al., 2014); Abd El Rehim et al.2016; Abdel-Fatah et al. 2016; Abdel-Fatah et al. 2017; Quraishi and Jamal 2001). 1,8-Naphthalimide derivatives can be easily prepared by imidation of 1,8-naphthalic anhydrides with suitable amines, to achieve various functionalized derivatives of imide nitrogen. In this study, 2-(2-hydroxyethyl)benzo[de] isoquinoline-1,3-dione (HBIQ) that carry hetero atoms like $\mathrm{N}$ and $\mathrm{O}$ as well as conjugated $\pi$-electrons was prepared to probe the inhibition of MS corrosion in $1 \mathrm{M}$ SA medium through electrochemical approaches. The activation and thermodynamic parameters of the corrosion inhibition process, surface characterization and spectroscopic investigations were performed to arrive at the mechanism of corrosion inhibition using HBIQ. In addition, the quantum chemical calculations were performed to give basic insights into the mode of HBIQ action, as well as to validate the experimental results.

\section{Experimental}

\section{Material, medium and inhibitor preparation}

Test coupons of MS with composition (\%weight) of $\mathrm{Fe}$ (98.51), C (0.432), Si (0.187), Mn (0.77), P (0.0085), S (0.011), Cr (0.011), Ni (0.0063), Mo (0.019), $\mathrm{Al}(0.039)$ and $\mathrm{Cu}(0.0015)$ were employed for the present study. Acenaphthene was oxidized in presence of potassium dichromate in glacial acetic acid and the formed 1,8-napthalic anhydride product was allowed to undergo imidation using ethanolamine to obtain HBIQ (Huang et al. 2019) which was characterized by Infrared spectrophotometry (Schimadzu FTIR 8400S Spectrophotometer). The synthetic method for the preparation of HBIQ is presented in Supplementary Figure (SF.1), respectively.

2-(2-Hydroxyethyl)-1H-benzo[de]isoquinoline1,3(2H)-dione (HBIQ): Off white solid; yield: 78\%; m.p.: $178-180{ }^{\circ} \mathrm{C}$; FT-IR $\left(\mathrm{cm}^{-1}\right): 3473,2961,2873,1695$, 1684, 1622 (SF.2); ${ }^{1} \mathrm{HNMR}$ (400 MHz, DMSO-d 6 , ppm): 3.606-3.654 (q, 2H, $\left.\mathrm{CH}_{2}\right), 4.149-4.182\left(\mathrm{t}, 2 \mathrm{H}, \mathrm{CH}_{2}\right)$, 4.804-4.834 (t, OH), 7.860-8.513 (6. Ar.H) (SF.3); MS of $\mathrm{C}_{14} \mathrm{H}_{11} \mathrm{NO}_{3}$ : 241 (SF.4).

The corrosive electrolyte (sulfamic acid) of $1 \mathrm{M}$ concentration was prepared by dissolving $97.5 \mathrm{~g} \mathrm{SA}$ in $1000 \mathrm{~mL}$ of double distilled water.

\section{Electrochemical measurements}

CH Instrument (USA Model 604D) with conventional threeelectrode thermostated cell assembly was used to carry out the electrochemical measurements. A $\mathrm{Hg}-\mathrm{Hg}_{2} \mathrm{Cl}_{2}$ (calomel) was used as reference electrode, platinum as counter electrode and MS coupons as working electrode. Prior to each test, the MS test coupon was dipped in SA solution and steady-state open-circuit potential (OCP) was allowed to establish at the end of $30 \mathrm{~min}$. In EIS technique, small amplitude ac signal of $10 \mathrm{mV}$ was applied to the electrochemical system in the frequency range of $10 \mathrm{kHz}$ to $0.01 \mathrm{~Hz}$ at the $\mathrm{OCP}$, and the response to the input signal was recorded in the form of Nyquist plots. In PP method the potential of the MS specimen was ramped $\pm 0.25 \mathrm{~V}$ with respect to OCP and the anodic and cathodic curves were obtained at a scan 
rate of $1 \mathrm{mVS}^{-1}$. The corrosion current density $\left(i_{\text {corr }}\right)$ values were calculated by the extrapolation of the anodic and cathodic slopes in the presence and absence of HBIQ, which were further used to calculate corrosion rate (CR), surface coverage $(\theta)$ and inhibition efficiency (IE).

\section{Computational study}

Gaussian maestro material science software with the basic set (B3LYP) and 631+G was used to acquire the DFT calculations. The optimized structure of HBIQ molecule with HOMO and LUMO levels were obtained by 2D and 3D molecule builders. The energies of the highest occupied $\left(E_{\mathrm{HOMO}}\right)$ and lowest unoccupied $\left(E_{\mathrm{LUMO}}\right)$ molecular orbitals were then used to evaluate other quantum chemical parameters.

\section{Spectral analysis of HBIQ adsorption}

\section{Ultraviolet-Visible (UV/Vis) spectral studies}

Shimadzu 1800 UV-Visible spectrophotometer was used to record the UV/visible spectra of 1 M SA containing HBIQ $\left(1 \times 10^{-4} \mathrm{M}\right)$. The absorption spectrum of the same solution was further recorded after immersing MS specimen for $3 \mathrm{~h}$.

\section{Fourier transform Infra-red spectral analyses}

Shimadzu IR spirit spectrophotometer was used to record the FTIR spectrum of HBIQ molecule and the scraped out product of the adsorbed protective layer formed on the MS surface exposed to $7.5 \times 10^{-4} \mathrm{M}$ HBIQ in $1 \mathrm{M} \mathrm{SA}$ acid solution.

\section{Surface characterization}

Freshly polished MS metal coupons were introduced in $1 \mathrm{M}$ SA solution in the absence and presence of HBIQ to carry out surface morphological studies using JEOL JSM-6380L scanning electron microscope (SEM) and 1B342 Innova atomic force microscope (AFM).

\section{Results and discussion}

\section{Potentiodynamic polarization (PP) method}

The influence of different concentrations of HBIQ on MS corrosion inhibition was monitored by PP technique. Tafel plots of MS in $1 \mathrm{M} \mathrm{SA}$ solution, both in the absence and the presence of HBIQ, are shown in Fig. 1a. The parameters such as corrosion potential $\left(E_{\text {corr }}\right)$, corrosion current density $\left(i_{\text {corr }}\right)$, cathodic $\left(\beta_{\mathrm{c}}\right)$ and anodic Tafel slope $\left(\beta_{\mathrm{a}}\right)$ were obtained from the plot. The $i_{\text {corr }}$ values were then used to calculate the corrosion rate (CR) and inhibition efficiency (IE) using Eqs. 1 and 2, respectively, and are presented in Table 1

$\mathrm{CR}\left(\mathrm{mmy}^{-1}\right)=\frac{3270 \times \mathrm{EW} \times i_{\text {corr }}}{d}$

where 3270 is a constant that defines the unit for the $\mathrm{CR}, d$ expressed in $\mathrm{g} / \mathrm{cm}^{3}$ and $\mathrm{EW}$ are the density and the equivalent weight of corroding metal, respectively (Kumari et al.2017a, b; Kumari et al. 2020a, b) (a)

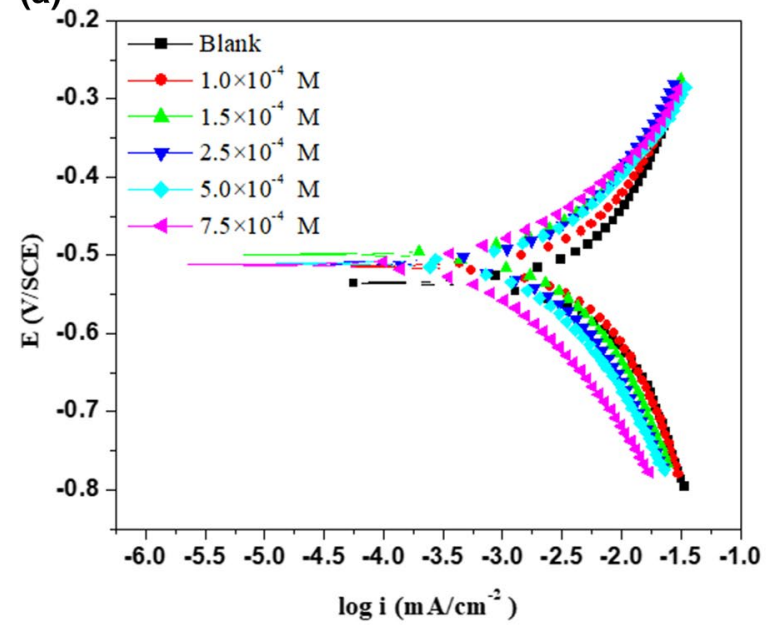

(b)

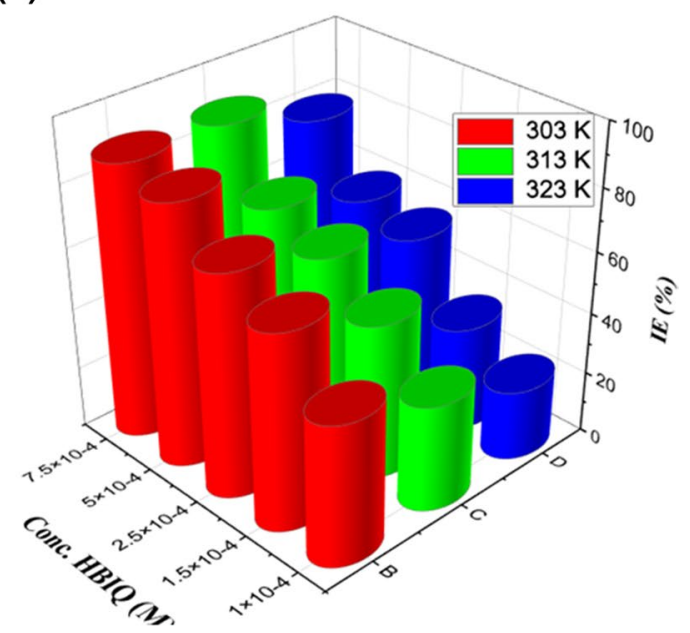

Fig. 1 a Tafel plots for the corrosion of MS in $1 \mathrm{M} \mathrm{SA}$ at $313 \mathrm{~K}$ in the absence and presence of HBIQ and $\mathbf{b}$ the 3D plots for the variation of \%IE with varying concentrations of HBIQ at different temperatures 
Table 1 Results of PP experiments for the corrosion of MS in 1 M SA in the absence and presence of HBIQ at different temperatures

\begin{tabular}{|c|c|c|c|c|c|c|c|}
\hline Temp (K) & Conc. Of HBIQ (M) & $E_{\text {corr }}(\mathrm{V} / \mathrm{SCE})$ & $-\beta_{\mathrm{c}}\left(\mathrm{mV} \mathrm{dec}{ }^{-1}\right)$ & $\beta_{\mathrm{a}}\left(\mathrm{mV} \mathrm{dec}{ }^{-1}\right)$ & $\begin{array}{l}i_{\text {corr }} \\
\left(\times 10^{-3} \mathrm{~mA} \mathrm{~cm}^{-2}\right)\end{array}$ & CR (mpy) & $\%$ IE \\
\hline \multirow[t]{6}{*}{303} & 0 & -0.535 & 52.86 & 49.74 & 4.724 & 1095 & - \\
\hline & $1 \times 10^{-4}$ & -0.524 & 53.41 & 55.96 & 2.555 & 592.4 & 45.91 \\
\hline & $1.5 \times 10^{4}$ & -0.507 & 78.67 & 62.65 & 1.711 & 396.7 & 63.78 \\
\hline & $2.5 \times 10^{4}$ & -0.511 & 67.13 & 79.97 & 1.300 & 290.4 & 72.48 \\
\hline & $5 \times 10^{-4}$ & -0.518 & 68.15 & 80.64 & 0.621 & 144.1 & 85.0 \\
\hline & $7.5 \times 10^{4}$ & -0.518 & 72.32 & 89.03 & 0.459 & 89.36 & 89.0 \\
\hline \multirow[t]{6}{*}{313} & 0 & -0.523 & 51.22 & 49.68 & 5.963 & 1382 & - \\
\hline & $1 \times 10^{-4}$ & -0.514 & 52.31 & 54.95 & 3.902 & 927.1 & 34.56 \\
\hline & $1.5 \times 10^{4}$ & -0.499 & 57.31 & 61.44 & 2.925 & 566.6 & 50.54 \\
\hline & $2.5 \times 10^{4}$ & -0.510 & 56.36 & 66.12 & 2.112 & 512.9 & 62.90 \\
\hline & $5 \times 10^{-4}$ & -0.510 & 61.31 & 66.94 & 1.778 & 412.2 & 70.18 \\
\hline & $7.5 \times 10^{4}$ & -0.512 & 69.32 & 88.43 & 0.668 & 155.2 & 88.7 \\
\hline \multirow[t]{6}{*}{323} & 0 & -0.523 & 55.04 & 50.63 & 7.452 & 1728 & - \\
\hline & $1 \times 10^{-4}$ & -0.526 & 53.08 & 50.61 & 5.750 & 1371 & 22.83 \\
\hline & $1.5 \times 10^{4}$ & -0.509 & 51.38 & 54.46 & 4.911 & 1139 & 34.09 \\
\hline & $2.5 \times 10^{4}$ & -0.513 & 54.71 & 58.33 & 3.421 & 920 & 55.30 \\
\hline & $5 \times 10^{-4}$ & -0.503 & 56.49 & 63.34 & 2.974 & 553.9 & 60.00 \\
\hline & $7.5 \times 10^{4}$ & -0.503 & 61.76 & 77.35 & 1.577 & 365.5 & 78.83 \\
\hline
\end{tabular}

$\mathrm{IE}(\%)=\frac{i_{\text {corr }}-i_{\text {corr(inh })}}{i_{\text {corr }}} \times 100$

where, $i_{\text {corr }}$ and $i_{\text {corr(inh) }}$ signify the current density values for the corrosion process in the absence and presence of HBIQ, respectively (Yadav et al. 2016).

Tafel plots confirmed that the addition of HBIQ to SA solution leads to a substantial reduction in the CR, i.e., shifts the cathodic and anodic current curves toward the lower current densities. HBIQ exerted a concentration-dependent IE with a maximum of $89 \%$ at $7.5 \times 10^{-4} \mathrm{M}$. The decrease in $i_{\text {corr }}$ and CR values with increase in HBIQ concentration indicated the role of HBIQ in delaying the anodic and cathodic reactions that occur during the course of acid corrosion. Further, the increase in IE is essentially attributed to the formation of protective HBIQ passive films on the MS surface, thereby blocking the cathodic and anodic reaction sites (Kumari et al. 2015). Thus, the HBIQ molecules adsorbed on to the reactive sites of the metal surface play an important role in reducing the corrosion process. It is also observed that both cathodic $\left(\beta_{\mathrm{c}}\right)$ and anodic $\left(\beta_{\mathrm{a}}\right)$ Tafel lines are parallel and there is no significant variation in the slope values in the inhibited solution compared to uninhibited. This suggested that the corrosion inhibition is through simple adsorption without affecting the inhibition mechanism (Li et al. 2007).

Further, the effect of temperature on the $i_{\text {corr }}, \mathrm{CR}$ and IE was investigated. The $i_{\text {corr }}$ and CR values increased with increase in temperature in the absence of HBIQ owing to the increase in the conductance of SA medium resulting in increased hydrogen evolution reaction at the cathodic region (Wang et al. 2010). However, the addition of HBIQ to the medium showed not only a remarkable decrease in $i_{\text {corr }}$, and CR values, but also increase in the IE values at each temperature. However, for a specific concentration of HBIQ, the \% IE decreased with increase in temperature. At lower temperature, the adsorption of HBIQ completely shielded the MS surface, thereby exhibiting good IE, whereas at higher temperature the \% IE slightly decreased. This behavior is attributed to the desorption of adsorbed HBIQ molecules from the MS surface, further exposing the fresh surface to the corrosive medium (Pinto et al. 2011). The variation of \% IE with varying concentrations of HBIQ at various temperatures is presented in Fig. 1b.

The influence of temperature on the corrosion rate is also one of the most important factors that affects the kinetic parameters such as energy of activation $\left(E_{\mathrm{a}}\right)$, enthalpy of activation $\left(\Delta H^{\#}\right)$, and entropy of activation $\left(\Delta S^{\#}\right) . E_{\mathrm{a}}$ was calculated using Arrhenius Eq. 3 (Kumari et al. 2020a, b).

$\ln (\mathrm{CR})=B-\frac{E_{\mathrm{a}}}{R T}$

where $R$ is the gas constant in $\mathrm{kJmol}^{-1}$ and $T$ is the temperature in Kelvin. The Arrhenius plot for the corrosion of mild steel at different concentration of HBIQ in $1 \mathrm{M} \mathrm{SA}$ is shown in Fig. 2a. The slop of the straight line plots gives 

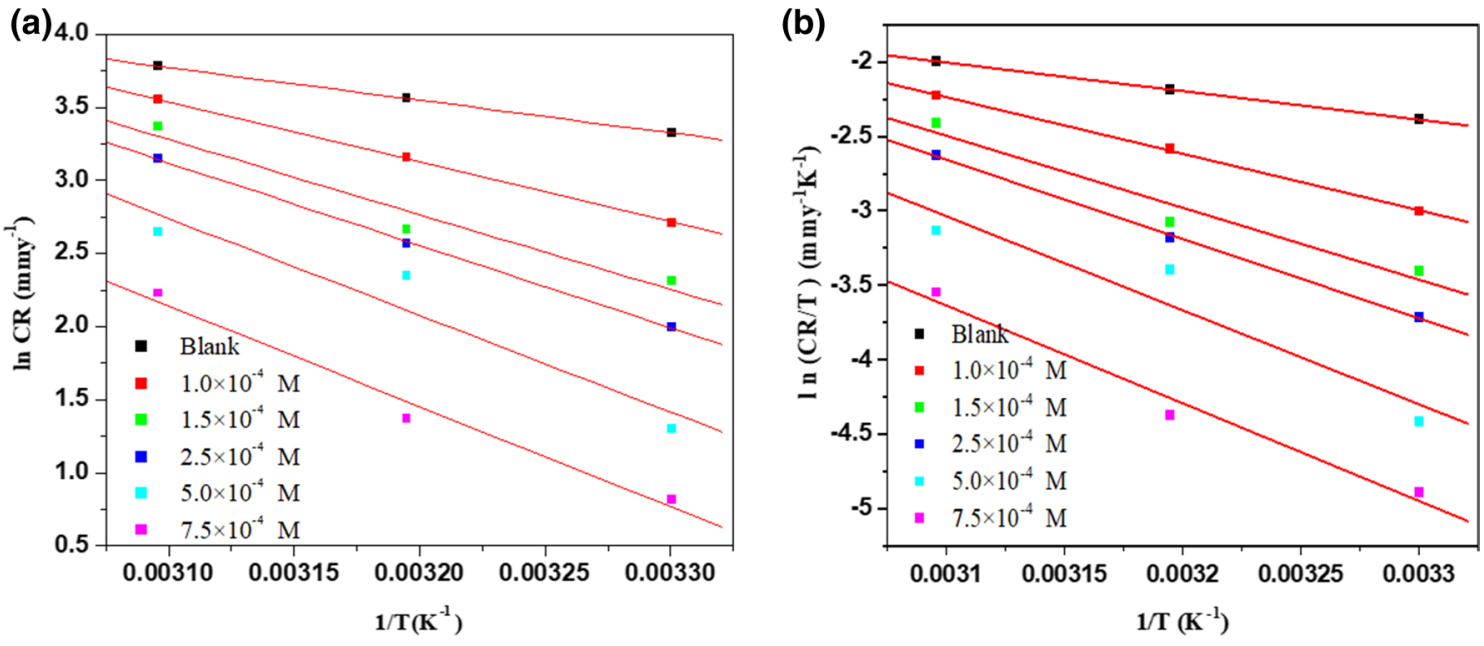

Fig. 2 a Arrhenius plot, b Plots of $\ln (\mathrm{CR} / T)$ verses $1 / T$ for corrosion MS in 1 M SA at different concentration of HBIQ

Table 2 Activation parameters for the corrosion of MS in $1 \mathrm{M}$ SA having different inhibitor concentration

\begin{tabular}{llll}
\hline $\begin{array}{l}\text { Conc. of HBIQ } \\
(\mathrm{M})\end{array}$ & $E_{\mathrm{a}}(\mathrm{kJmol}-1)$ & $\Delta H^{\#}(\mathrm{~kJ} / \mathrm{mol})$ & $\Delta S^{\#}\left(\mathrm{~J} \mathrm{~mol}^{-1} \mathrm{~K}^{-1}\right)$ \\
\hline 0 & 18.59 & 15.96 & -164.7 \\
$1 \times 10^{-4}$ & 34.15 & 31.55 & -118.3 \\
$1.5 \times 10^{-4}$ & 42.75 & 40.15 & -93.81 \\
$2.5 \times 10^{-4}$ & 46.96 & 44.29 & -82.31 \\
$5 \times 10^{-4}$ & 55.09 & 52.49 & -60.03 \\
$7.5 \times 10^{-4}$ & 57.16 & 54.56 & -58.62 \\
\hline
\end{tabular}

$\left(-E_{\mathrm{a}} / R\right)$, from which $E_{\mathrm{a}}$ was calculated. The obtained $E_{\mathrm{a}}$ values along with the enthalpy and entropy of activation values are listed in Table 2.

The $E_{\mathrm{a}}$ values increased with rise in HBIQ concentration, which suggested that at larger HBIQ concentration, the corrosion reaction will be pushed to the surface sites with higher $E_{\mathrm{a}}$ values. This indicated the formation of a barrier layer through the inhibitor adsorption on the MS surface, which can hinder metal dissolution process. The larger values of $E_{\mathrm{a}}$ compared to the blank also pointed towards the reduced adsorption tendency of HBIQ with rise in temperature leading to the electrostatic interaction between the MS surface and HBIQ molecules (Rbaa et al 2020).

The entropy $\left(\Delta S^{\#}\right)$ and enthalpy $\left(\Delta H^{\#}\right)$ of activation for dissolution of metal was determined using the transition state Eq. 4 (Kumari et al. 2014)

$\mathrm{CR}=\frac{R T}{N h} \exp \left(\frac{\Delta S^{\#}}{R T}\right) \exp \left(\frac{-\Delta H^{\#}}{R T}\right)$

where $h$ is Planck's constant and $N$ is Avogadro's number. The plot of $\ln (\mathrm{CR} / T)$ verses $1 / T$ for $\mathrm{MS}$ in $1 \mathrm{M}$
SA in different concentrations of HBIQ (Fig. 2b) with slope $=\Delta H^{\#} / \mathrm{R}$ and intercept $=\ln (R / N h)+\left(\Delta S^{\#} / R\right)$ was used to calculate changes in entropy $\left(\Delta S^{\#}\right)$ and enthalpy $\left(\Delta H^{\#}\right)$. The $\Delta S^{\#}$ values were found to be large and negative, which suggested towards increased order in the system when the reactants were associated to form activated complex in the rate determining step (Fouda et al.2017).

\section{Electrochemical impedance spectroscopy (EIS)}

EIS technique provides not only more insight into the corrosion mechanism, but also kinetic evidence for the electrochemical system under investigation. The Nyquist plots obtained for the corrosion of MS in $1 \mathrm{M} \mathrm{SA}$ at $303 \mathrm{~K}$ is displayed in Fig. 3a. Similar plots were attained at 313 and $323 \mathrm{~K}$ also. The shape of the Nyquist plots remained the same, both in the absence and presence of HBIQ, which indicated that its presence increases the impedance towards corrosion process without affecting any other aspects of the corrosion behavior (Khaled 2008). The Nyquist plots contained a single depressed semicircle loop at the high frequency region with a remarkable deviation from an ideal semicircle. The depressed feature is due to the surface inhomogeneity that arises when the corrosion product is deposited on the MS surface (Charita and Rao 2017). The electrical capacity is decreased due to the adsorption of the HBIQ molecules by replacing the initially adsorbed water molecules from the metal surface. This change widens the diameter of the capacitive loop with increase in the HBIQ concentration, which pointed towards the increased resistance of the metal towards the charge transfer process (Amin et al. 2007). This can be ascribed to the formation of protective film of HBIQ on the MS surface that creates a barrier for mass and charge-transfer. 
(a)

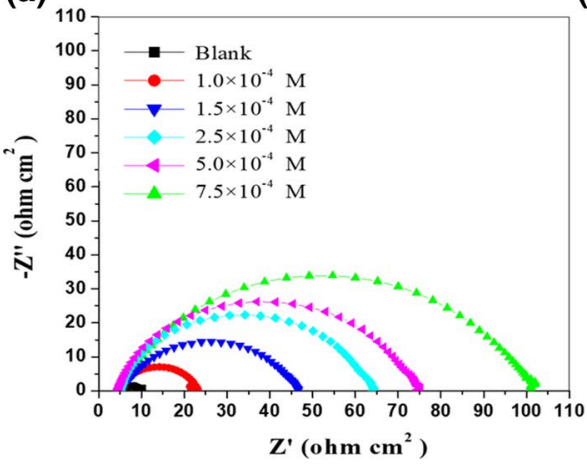

(b)

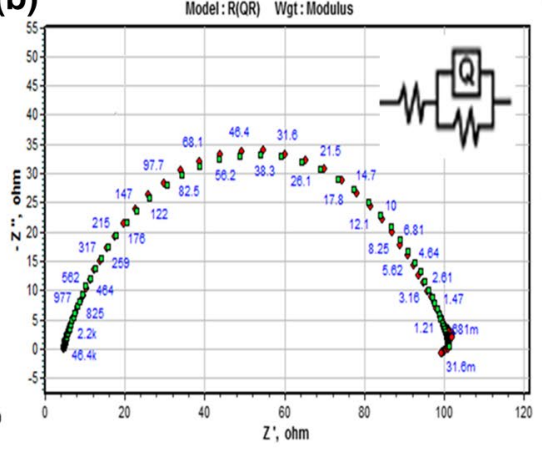

(c)

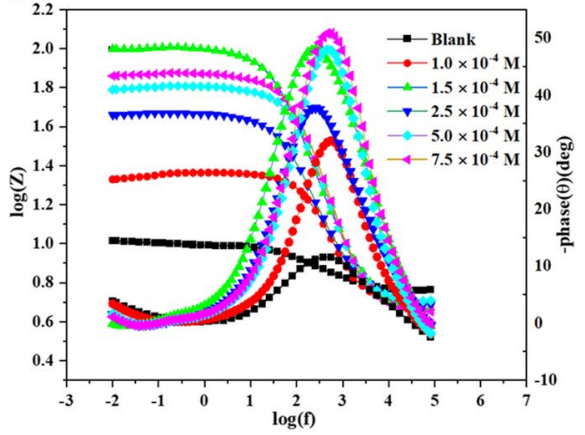

Fig. 3 a Nyquist plot of MS in 1 M SA at different concentrations of HBIQ at $303 \mathrm{~K}$, b Equivalent circuit used to analyze the impedance data, and $\mathbf{c}$ Bode plots MS in $1 \mathrm{M} \mathrm{SA}$ at different concentrations of HBIQ at $303 \mathrm{~K}$

In order to evaluate the mathematical simulations of the impedance plot, the Nyquist plots were fitted with the equivalent circuit. A simple Randle's equivalent circuit (RQR) as shown in Fig. 3b was used to analyze the data. The circuit composed of two resistances $R_{\mathrm{S}}$ and $R_{\mathrm{ct}}$ offered by the solution and charge transfer process, respectively, and one constant phase element $(Q)$. The results are presented in Table 3.

From Table 3 it is found that $R_{\mathrm{ct}}$ values increased with increase in HBIQ concentration, which indicated that charge transfer process mainly controls the corrosion process. The HBIQ molecules adsorbed on to the metal surface form a protective layer and decrease the corrosion rate. The $R_{\mathrm{ct}}$ values were further used to calculate the percentage inhibition efficiency using Eq. 5, (Ahmed et al. 2018)
$\% \mathrm{IE}=\frac{R_{\mathrm{ct}(\mathrm{inh})}-R_{\mathrm{ct}}}{R_{\mathrm{ct}(\mathrm{inh})}} \times 100$

where $R_{\mathrm{ct}}$ and $R_{\mathrm{ct}(\mathrm{inh})}$ represent the resistance of polarization for the uninhibited and inhibited solutions, respectively. The constant phase element, $Q$ was introduced in the circuit instead of a pure double layer capacitor to provide more accurate fit for Nyquist plot. The $Q$ impedance $\left(Z_{\mathrm{Q}}\right)$ was calculated using Eq. 6, (Kumari et al 2017a, b).

$Z_{Q}=Q^{-1}\left(i w_{\max }\right)^{-n}$

where, $Q$ is the proportionality coefficient, $w_{\max }$ is the angular frequency, $I$ is the imaginary number and $n$ is the exponent related to the phase shift. The values of phase shift
Table 3 Results of EIS measurements in $1 \mathrm{M} \mathrm{SA}$ at different concentrations of HBIQ at different temperature for corrosion of MS

\begin{tabular}{llllll}
\hline Temp $(\mathrm{K})$ & Conc. of HBIQ $(\mathrm{M})$ & $R_{\mathrm{ct}}\left(\mathrm{ohm} \mathrm{cm}^{2}\right)$ & chi-squared values & $C_{\mathrm{dl}}\left(\mu \mathrm{F} \mathrm{cm}^{-2}\right)$ & $\% \mathrm{IE}$ \\
\hline 303 & 0 & 10.20 & $9.093 \times 10^{-4}$ & 10,634 & - \\
& $1 \times 10^{-4}$ & 18.18 & $2.300 \times 10^{-4}$ & 1221 & 43.89 \\
& $1.5 \times 10^{-4}$ & 30.5 & $4.794 \times 10^{-4}$ & 491.1 & 66.56 \\
& $2.5 \times 10^{-4}$ & 42.11 & $5.155 \times 10^{-4}$ & 254.8 & 75.78 \\
& $5 \times 10^{-4}$ & 69.3 & $5.064 \times 10^{-4}$ & 104.2 & 85.28 \\
& $7.5 \times 10^{-4}$ & 97.29 & $3.809 \times 10^{-4}$ & 62.92 & 89.52 \\
& 0 & 6.2 & $9.011 \times 10^{-4}$ & 23,980 & - \\
313 & $1 \times 10^{-4}$ & 8.97 & $8.842 \times 10^{-4}$ & 6204 & 30.88 \\
& $1.5 \times 10^{-4}$ & 12.66 & $3.284 \times 10^{-4}$ & 2507 & 51.03 \\
& $2.5 \times 10^{-4}$ & 19.29 & $9.722 \times 10^{-4}$ & 1150 & 67.83 \\
& $5 \times 10^{-4}$ & 23.92 & $3.162 \times 10^{-4}$ & 731.9 & 74.08 \\
& $7.5 \times 10^{-4}$ & 42.93 & $3.284 \times 10^{-4}$ & 231.2 & 85.56 \\
& 0 & 3.50 & $7.669 \times 10^{-4}$ & 80,666 & - \\
& $1 \times 10^{-4}$ & 4.56 & $9.328 \times 10^{-4}$ & 26,394 & 23.25 \\
& $1.5 \times 10^{-4}$ & 5.51 & $2.987 \times 10^{-4}$ & 12,548 & 36.48 \\
& $2.5 \times 10^{-4}$ & 8.10 & $3.862 \times 10^{-4}$ & 5444 & 56.79 \\
& $5 \times 10^{-4}$ & 11.15 & $1.043 \times 10^{-4}$ & 3249 & 68.61 \\
& $7.5 \times 10^{-4}$ & 20.75 & $9.619 \times 10^{-5}$ & 1016 & 83.13 \\
\hline
\end{tabular}


(n) lies between 0 and $1(0 \leq n \leq 1)$. If $n=1$, then $Q$ behaves as ideal capacitive behavior. The correction in the capacitance to its real value $\left(C_{\mathrm{dl}}\right)$ was calculated using Eq. 7 (ElHaddad and Elattar 2015).

$C_{\mathrm{dl}}=\frac{1}{2 \pi f_{\max } R_{\mathrm{ct}}}$

where $f_{\max }$ is the frequency at which the imaginary constituent of impedance is maximum. $C_{\mathrm{dl}}$ decreased with increase in HBIQ concentration. The capacitance values are inversely proportional to the thickness of the electrical double layer formed at the metal solution interface. The thickness of the double layer increased due to the adsorption of larger inhibitor molecules by replacing the initially adsorbed water molecules from the metal surface (Lebrini et al. 2011).

The Bode plots for the corrosion MS in 1 M SA solution are shown in Fig. 3c. The plots phase angle versus frequency shows one peak measured at the absence of HBIQ maximum at around $-10^{\circ}$, further the subsequent peaks moved slightly to lower frequencies and increased the maximum phase angle with increase in the HBIQ concentration, up to around $-50^{\circ}$. The plots modulus of impedance $|\mathrm{Z}|$ versus frequency displayed the presence of two plateaus: one at high frequency and the other at low frequency, and one negative slope along the spectra that was associated with the semicircles shown in the Nyquist plot. The plateaus observed at high frequency are related to the solution resistance of the system, $R s$ and that of low frequency plateaus are associated to the charge transfer resistance (Bhuvneshvari et al. 2020). Moreover, the shapes of the Nyquist and Bode plots are similar in the absence and presence of inhibitor, which indicated that HBIQ does not influence on the corrosion mechanism.

\section{Adsorption isotherm}

Generally, there are three possible ways of adsorption of inhibitor molecules on to the metal surface; physisorption, chemisorption and mixed adsorption. The adsorption phenomenon of any inhibitor can be defined by studying the adsorption isotherms. For HBIQ, various adsorption isotherm models such as Frumkin, Temkin, Freundlich and Langmuir were attempted to fit the values of surface coverage $(\theta)$, which was calculated using Eq. 8 (Al-Azawi. et al. 2018).

$\theta=\% \mathrm{IE} / 100$

The plots of $C_{\text {inh }} / \theta$ versus $C_{\text {inh }}$ depicted in Fig. 4 showed a straight line with slope and correlation coefficient $R^{2}$ values nearly equal to one, which specified that the adsorption of HBIQ on to the MS surface obeyed Langmuir's isotherm model (Boudjellal et al 2020) as given by Eq. 9.

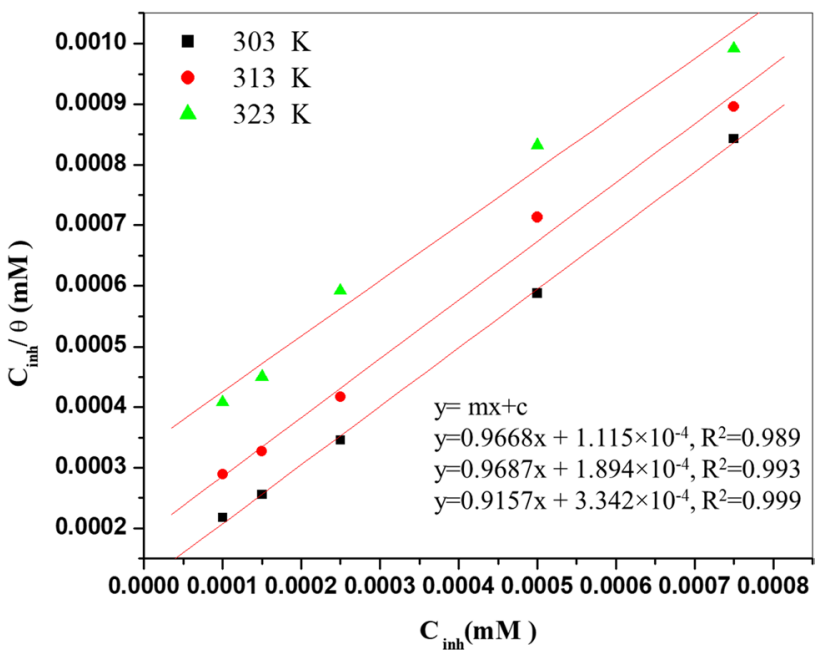

Fig. 4 Langmuir adsorption isotherm for mild steel in 1 M SA using different inhibitor concentration

Table 4 Thermodynamic parameters for adsorption of HBIQ on MS in $1 \mathrm{M} \mathrm{SA}$ at different temperature

\begin{tabular}{lllll}
\hline Temp $(\mathrm{K})$ & $K_{\text {ads }}\left(\mathrm{M}^{-1}\right)$ & Slope & $R^{2}$ & $\Delta G_{\text {ads }}^{\circ}\left(\mathrm{KJ} \mathrm{mol}^{-1}\right)$ \\
\hline 303 & 5444.3 & 0.978 & 0.989 & -32.83 \\
313 & 3181.5 & 0.973 & 0.993 & -32.44 \\
323 & 9730.2 & 0.980 & 0.999 & -33.25 \\
\hline
\end{tabular}

$\frac{C_{\text {inh }}}{\theta}=\frac{1}{K}+C_{\text {inh }}$

where, $K$ and $C_{\text {inh }}$ represent the adsorptive equilibrium constant and the concentration of inhibitor, respectively. The $K_{\text {ads }}$ values are related to standard free energy of adsorption $\left(\Delta G^{\circ}\right.$ ads $)$ as given by Eq. 10 and recorded in Table 4.

$K=\frac{1}{55.5} \exp \left(\frac{-\Delta G_{\text {ads }}^{\circ}}{R T}\right)$

where T, R, $\Delta G^{\circ}$ ads and 55.5 represent the absolute temperature, the universal gas constant, free energy of adsorption and the concentration of water in solution in mol $\mathrm{dm}^{-3}$, respectively (Mistry and Jauhari 2013). Generally, if $\Delta G^{\circ}$ ads values are leas negative than $-20 \mathrm{kJmol}^{-1}$, then physical adsorption is favored between the charged inhibitor molecule and charged metal surface, whereas chemical adsorption occurs if the $\Delta G^{\circ}$ ads values are more negative than $-40 \mathrm{kJmol}^{-1}$ (Saliyan and Adhikari 2008). The $\Delta G^{\circ}$ ads values for HBIQ in $1 \mathrm{M}$ SA solution at the three studied temperatures were found to be between -20 and $-40 \mathrm{~kJ} \mathrm{~mol}^{-1}$, which indicated mixed adsorption mode, 
with predominant physisorption? (Mistry and Jauhari 2015). The HBIQ molecules could be directly adsorbed on the MS surface through the electrostatic interactions between the negatively charged metal surface and the protonated HBIQ molecules. Besides, the adsorption of the HBIQ molecules through donor acceptor interactions between free electron pairs of $\mathrm{N}, \mathrm{O}$ atoms and $\pi$ electrons of multiple bonds and vacant $\mathrm{d}$ orbitals of iron are also possible.

\section{Corrosion inhibition mechanism}

The corrosion mechanism is a surface phenomenon that depends on various factors like molecular size of inhibitor, charge density and number of active sites on metal surface (Martinez and Stern 2002). The interaction between metal and inhibitor plays a very important role in protecting metal from corrosion. The HBIQ molecules get adsorbed on to the MS surface to reduce the corrosion rate. As the thermodynamic parameters revealed mixed type of adsorption mode, HBIQ molecules can interact either through electron transfer or by electrostatic interaction with the MS surface (Abdallah et al 2018; Abdel-Fatah et al.2017).

$$
\begin{aligned}
& \mathrm{Fe}^{2+}+\mathrm{H}_{2} \mathrm{NSO}_{3}^{-} \leftrightarrow\left[\mathrm{FeH}_{2} \mathrm{NSO}_{3}^{-}\right]_{\mathrm{ads}}+\mathrm{HBIQ}^{+} \\
& \quad \leftrightarrow\left[\mathrm{FeH}_{2} \mathrm{NSO}_{3}^{-} \mathrm{HBIQ}^{+}\right]_{\mathrm{ads}}+[\mathrm{Fe} \mathrm{HBIQ}]_{\mathrm{ads}}+\mathrm{H}_{2} \mathrm{NSO}_{3}^{-}
\end{aligned}
$$

The electrostatic interaction can take place through the following steps; (i) in SA medium the MS surface attains positive charge due to its dissolution, (ii) the sulfamate ions $\left(\mathrm{H}_{2} \mathrm{NSO}_{3}{ }^{-}\right)$formed are attracted towards the positively charged MS surface to form an electrical double layer and (iii) the double layer then favors the adsorption of protonated HBIQ molecules from the acidic solution through electrostatic interaction to form a protective film. Similarly, HBIQ molecules can also get adsorbed by donor acceptor interactions. The unshared electrons pairs of the heteroatoms and double bonds of HBIQ can form a chemical bond with the empty d-orbitals of the iron atom on MS surface leading to chemisorption (Popova et al 2003). The schematic representation for the electron pair transfer and electrostatic interaction is shown in Fig. 5.

\section{Theoretical calculations using DFT}

Studies using density functional theories can be applied to corrosion systems to acquire more information on various factors such as frontier molecular orbital electron density and charge distribution, which can be co-related to the adsorption tendency and inhibition efficiency of organic molecules. The computational studies provide theoretical framework for effective inhibition mechanism depending on the structure of inhibitor molecule and predict its adsorption mechanism on the metal surface. Frontier orbital theory (MOT) is very useful for predicting the adsorption capacity of an inhibitor molecule. The optimized structure, HOMO, LUMO, and Mulliken charges on HBIQ are depicted in Fig. 6. The geometry of inhibitor structure was fully optimized and the electronic parameters such as highest occupied $\left(E_{\mathrm{HOMO}}\right)$ and lowest unoccupied $\left(E_{\mathrm{LUMO}}\right)$ molecular orbitals energies and the energy gap between them $(\Delta E)$ were obtained. These values were used to compute other quantum chemical parameters which enable to relate the effect of structure of molecule on the inhibition activity (Aoufir et al. 2017).

The high $E_{\text {Номо }}$ values represent greater electron contribution capabilities of HBIQ to the d-orbitals of Fe in MS, whereas the low $E_{\text {LUMO }}$ values denote stronger electron acceptance tendencies from the metal (Obot et al 2015; Sastri and Perumareddi 1997). Thus high HOMO and low LUMO values enabled adsorption of HBIQ on to the metal surface (Sneha et al 2020). $\Delta E$ value was low in case of HBIQ, which suggested its highly reactive
Fig. 5 Schematic representation of $\mathbf{a}$ physical and $\mathbf{b}$ chemical mode of adsorption for the HBIQ molecule on the MS surface

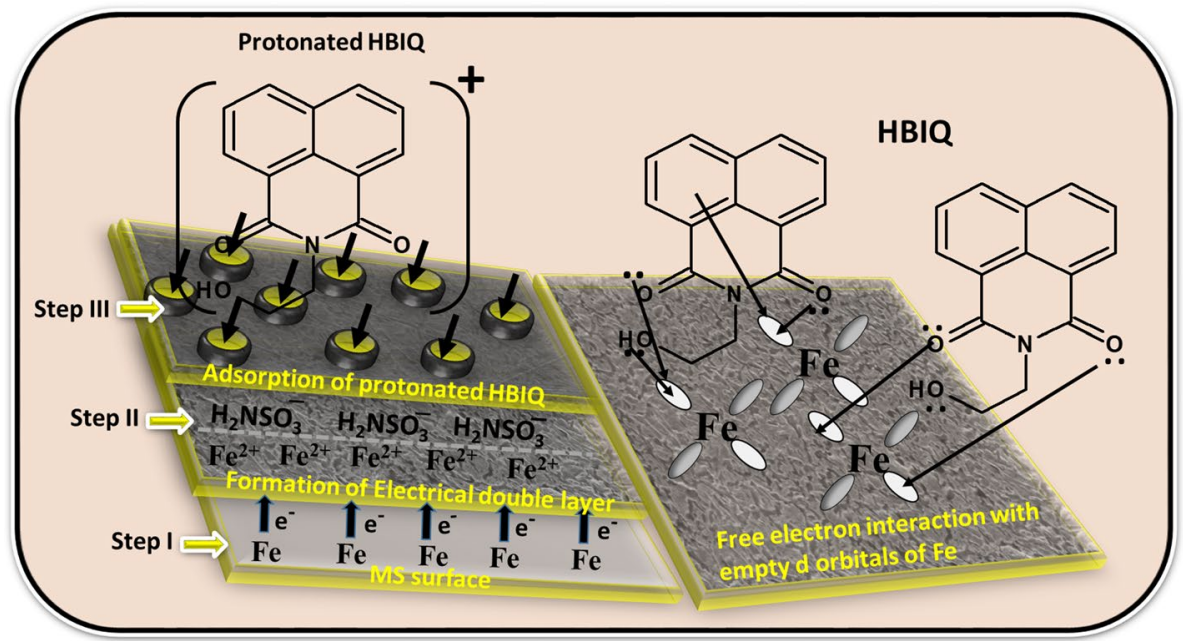


Fig. 6 a Optimized geometry $\mathbf{b}$ Mulliken charges, $\mathbf{c}$ HOMO and d LUMO levels of HBIQ (a)

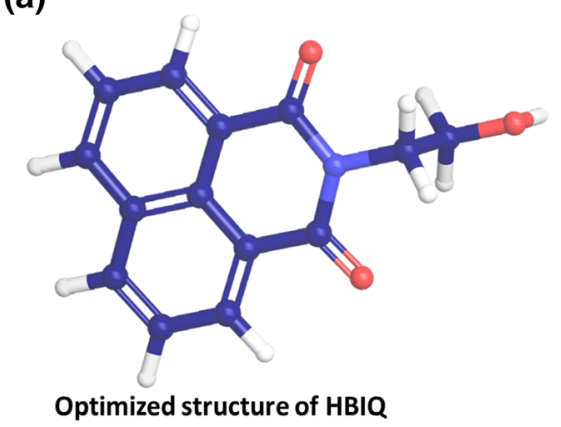

Optimized structure of HBIQ

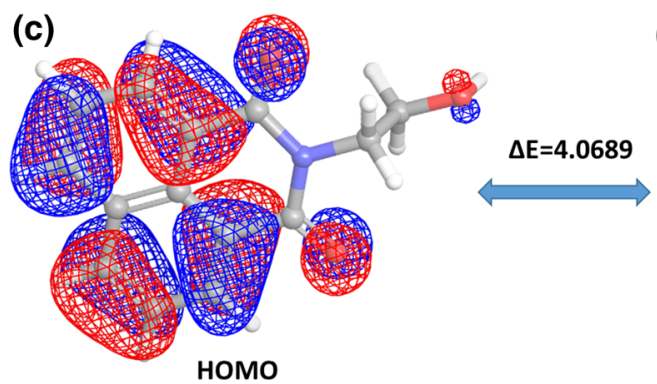

(b)

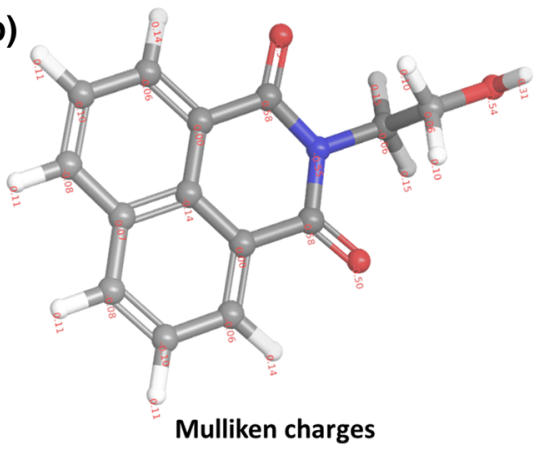

(d)

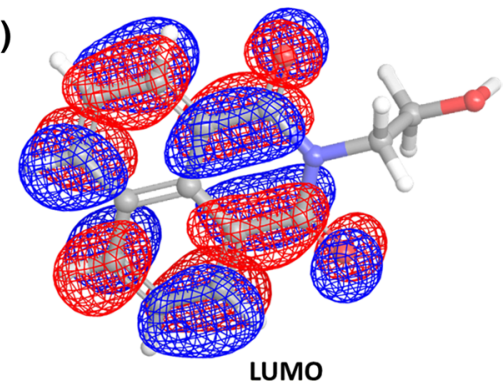

tendency (Wang et al. 2007). The ionization potential (I) value, which is the amount of energy required to remove an electron from a molecule (Obot et al. 2015) is related to energies of molecular orbitals according to the Koopmans theorem and is obtained from $I=-\mathrm{E}_{\mathrm{LumO}}$. The low $I$ value of HBIQ suggested easy removal of electron and hence high inhibition efficiency (Pearson 1986).

The other quantum chemical parameters could be used to describe the reactivity of HBIQ molecule such as absolute electronegativity $(\chi)$, chemical hardness $(\eta)$, softness $(\sigma)$, and the fraction of electron transfer $(\Delta N)$ calculated by applying Eqs.11-14, respectively, and are presented in Table 5 together with Mulliken charges on the HBIQ (Abd El Rehim. et al. 2001)

$\chi=1 / 2(I+A)$ $\eta=1 / 2(I-A)$

$\sigma=\frac{1}{\eta}$

$\Delta N=\frac{\phi_{\mathrm{Fe}}-\chi \operatorname{inh}}{2 \eta \operatorname{inh}}$

where $\varphi$ values indicates the work function. Chemical hardness and softness parameters are related to the description of the hard and soft acid/base as per the acid-base theory. A hard molecule has the least tendency to react, while a soft molecule has high tendency to react and hence soft molecules are expected to have the highest inhibition efficiency (Kikalj 2010). The tendency of the inhibitor molecule to donate the electrons to the metal surface is described based
Table 5 DFT parameters and Mulliken charges on the atoms of HBIQ

\begin{tabular}{|c|c|c|c|c|c|}
\hline \multicolumn{2}{|l|}{ DFT parameters } & \multicolumn{4}{|c|}{ Mulliken charges on atom } \\
\hline Property & Value & Atoms & Mulliken charges & Atoms & Mulliken charge \\
\hline $\mathrm{E}_{\text {номо }}$ & $-6.5198 \mathrm{eV}$ & $\mathrm{C} 1$ & -0.0604 & $\mathrm{C} 10$ & 0.0005 \\
\hline $\mathrm{E}_{\text {LUMO }}$ & $-2.4509 \mathrm{eV}$ & $\mathrm{C} 2$ & -0.1029 & $\mathrm{C} 11$ & 0.5849 \\
\hline Band gap $\left(E_{\mathrm{g}}\right)$ & $4.0689 \mathrm{eV}$ & $\mathrm{C} 3$ & -0.0833 & N12 & -0.5548 \\
\hline Ionization potential $(I)$ & 6.5198 & $\mathrm{C} 4$ & 0.0708 & $\mathrm{C} 13$ & 0.5848 \\
\hline Electron affinity (A) & 2.4509 & $\mathrm{C} 5$ & -0.1391 & 014 & -0.5020 \\
\hline Electronegativity $(\chi)$ & 4.4853 & C6 & 0.0015 & 015 & -0.5014 \\
\hline Global hardness $(\eta)$ & 2.0345 & $\mathrm{C} 7$ & -0.0830 & $\mathrm{C} 16$ & -0.0607 \\
\hline Global softness $(\sigma)$ & 0.4915 & $\mathrm{C} 8$ & -0.1030 & $\mathrm{C} 17$ & 0.0585 \\
\hline $\begin{array}{l}\text { Fractions of electron } \\
\text { transferred }(\Delta N)\end{array}$ & 0.0822 & C9 & -0.0605 & 018 & -0.5411 \\
\hline
\end{tabular}

Bold values indicate the hetero atoms with more negative Mulliken charge 
on the fraction of electron transferred $(\Delta N)$. The $\Delta N$ value of HBIQ being $0.0822(\Delta N>0)$, clearly suggested that the electron transfer occurs from the inhibitor to the metal surface (Kovačević and Kokalj 2011).

Mulliken charges on the atoms play vital role in predicting the adsorption spots of the inhibitor molecule and also the electron accepting and donating tendency between the metal surface and the inhibitor. It is reported (Gao and Liang 2007) that the hetero atoms with more negative Mulliken charge are considered as active sites for the adsorption process. As depicted in Table 5, the oxygen (O14, O15 and O18) and nitrogen (N12) atoms with more negative charge are found to be effective adsorption sites for the HBIQ molecule, thus preventing the corrosion of MS in SA solution.

\section{Spectral analysis of inhibitor adsorption}

UV-visible spectra were used to study the adsorption of HBIQ molecules on the metal surface as presented in Fig. 7a. Initially, absorption spectrum of 1 M SA containing $1 \times 10^{-4} \mathrm{M}$ HBIQ was recorded at room temperature, which displayed bands at 237, 265 and $340 \mathrm{~nm}$ due to $\pi \rightarrow \pi^{*}$ and $\mathrm{n} \rightarrow \pi^{*}$ transitions. Later the absorption spectrum of the test solution containing the same concentration of HBIQ in $1 \mathrm{M}$ SA was recorded after immersing MS coupon for about $1 \mathrm{~h}$. The spectrum showed a comparatively reduced absorption intensity, confirming the adsorption of some HBIQ molecules on MS surface.

FTIR measurements support in functional group identification and offer a qualitative idea about the adsorption of inhibitor molecules on the metal surface. FTIR spectra of HBIQ alone and the protective layer scraped out from the surface of MS specimen exposed to $7.5 \times 10^{-4} \mathrm{M}$ HBIQ in $1 \mathrm{M} \mathrm{SA}$ solution are depicted in Fig. 7b. A shift in the
$\mathrm{OH}$ absorption was observed from $3473 \mathrm{~cm}^{-1}$ of inhibitor to $3478 \mathrm{~cm}^{-1}$ of corroded product. In addition, the aliphatic and aromatic C-H stretching absorptions detected at $2873 \mathrm{~cm}^{-1}$ and $3067 \mathrm{~cm}^{-1}$ in the inhibitor were displaced to $2877 \mathrm{~cm}^{-1}$ and $3174 \mathrm{~cm}^{-1}$ in the corrosion product. These shifts in the IR frequencies of the functional groups present in inhibitor before and after adsorption to MS might be due to the metal-inhibitor interactions through functional groups.

\section{Surface morphology studies}

\section{Scanning electron microscopy (SEM), atomic force microscopy (AFM) and elemental analysis}

MS specimen was immersed in $1 \mathrm{M} \mathrm{SA}$ medium for $3 \mathrm{~h}$ in the absence and presence of inhibitor for surface topography analysis and the respective SEM and AFM images are depicted in Fig. 8. The uninhibited specimen (Fig. 8a) showed uneven surface with large number of pits due to the metal dissolution and deposition of corrosion product. However, the SEM image obtained in the presence of HBIQ inhibitor (Fig. 8b) displayed a smooth surface without any pits and cracks. This is due to the formation of protective layer of HBIQ on the metal surface, which could adsorb on almost all the pits and cavities, thereby reducing the corrosion rate. The three-dimensional AFM image (Fig. 8d) of specimen exposed to HBIQ in $1 \mathrm{M} \mathrm{SA}$ exhibited a smooth metal surface, when compared to that introduced in acid medium alone (Fig. 8c). The decrease in average surface roughness $\left(R_{\mathrm{a}}\right)$ and root-mean-square roughness $\left(R_{\mathrm{q}}\right)$ in the presence of inhibited solution when compared to uninhibited confirm the adsorption of HBIQ on to the metal surface. The $R_{\mathrm{a}}$ and $R_{\mathrm{q}}$ values are given in the table presented in Fig. 8.
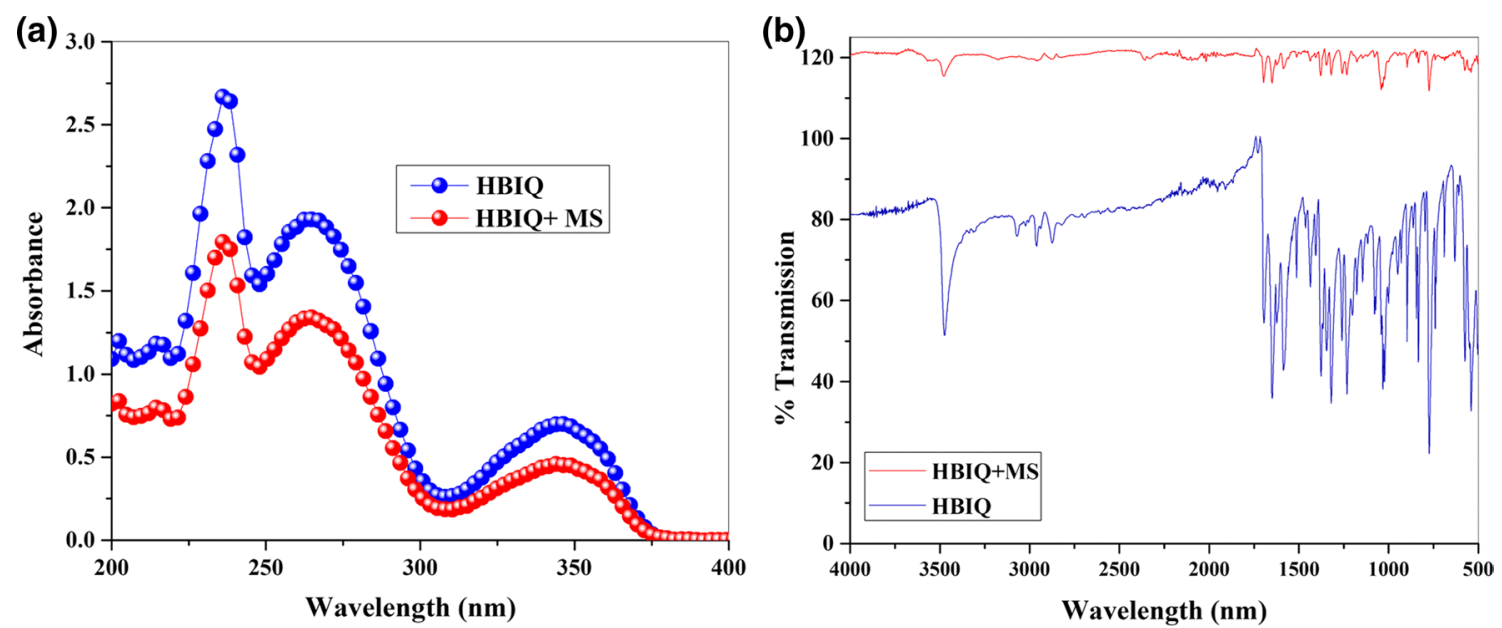

Fig. 7 a Overlay of absorption spectra of $1 \times 10^{-4}$ M HBIQ solution without and with MS coupon immersed in 1 M SA solution and b Overlay of the IR spectra of HBIQ and adsorption product formed on MS in $7.5 \times 10^{-4} \mathrm{M}$ HBIQ in $1 \mathrm{M}$ SA solution 

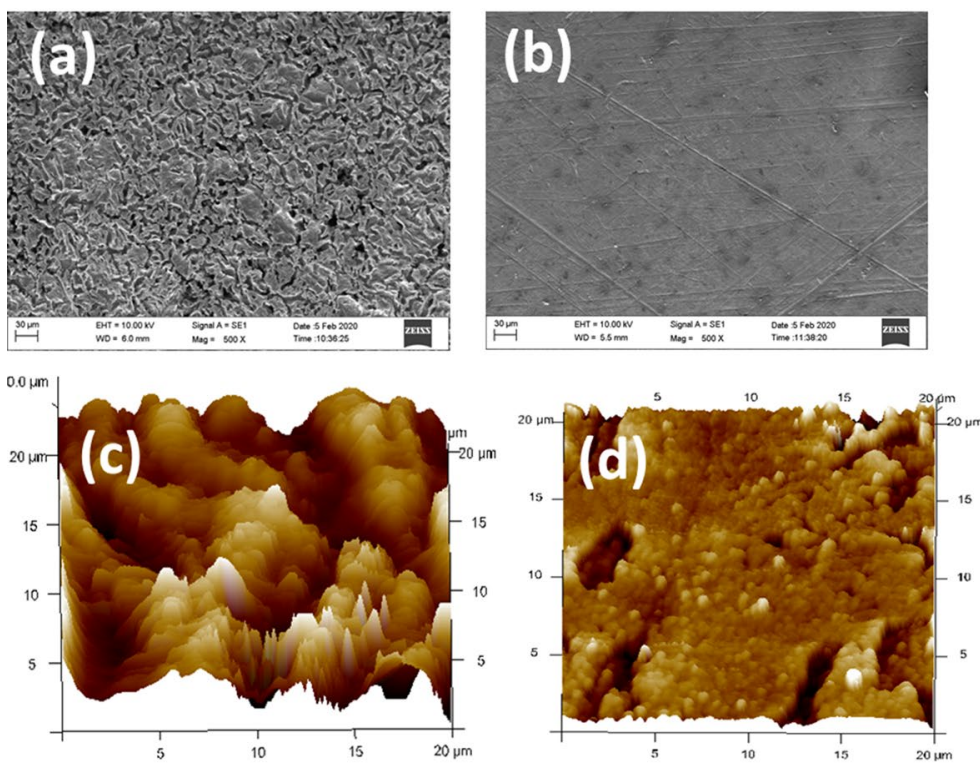
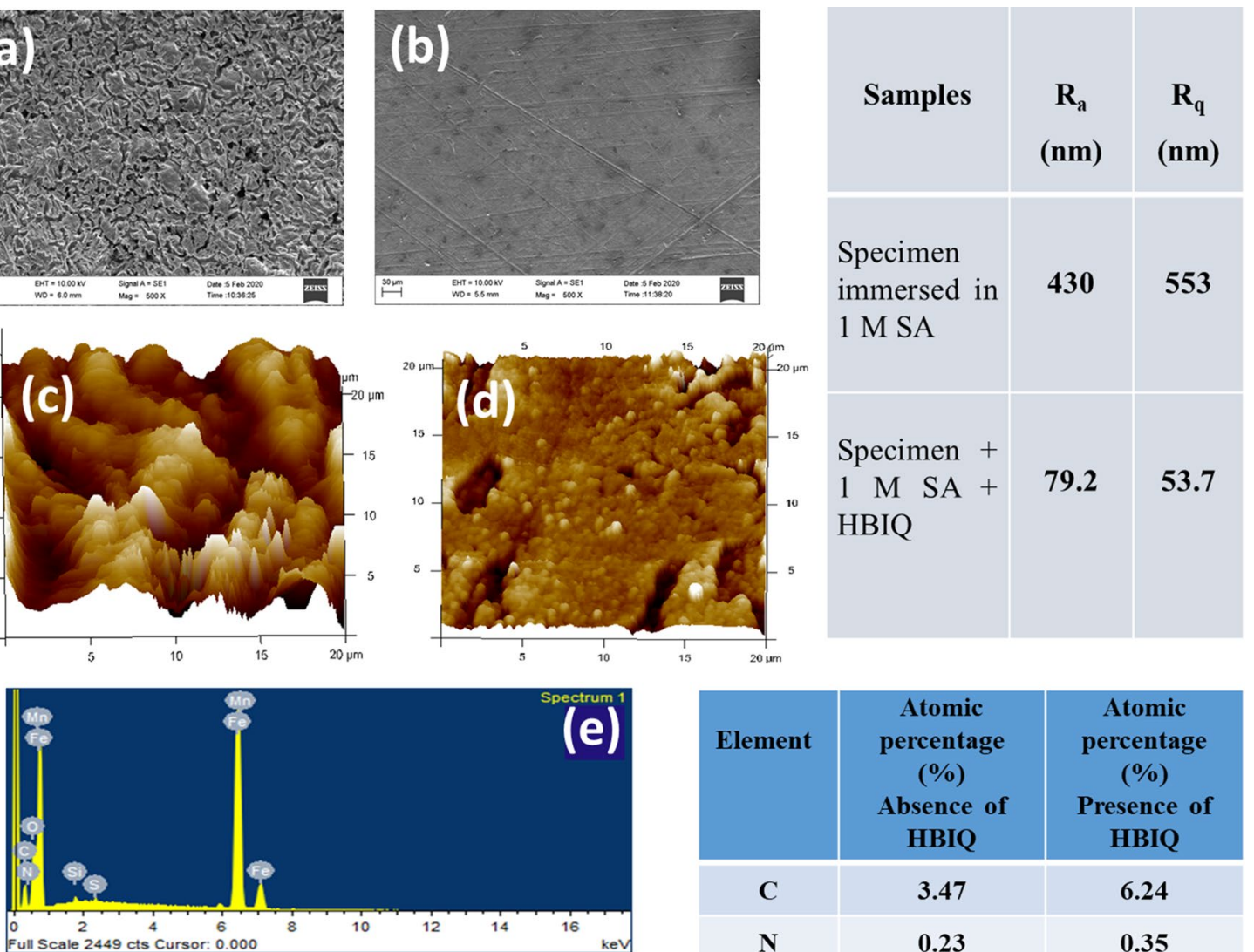

\begin{tabular}{|c|c|c|}
\hline Element & $\begin{array}{c}\text { Atomic } \\
\text { percentage } \\
(\%) \\
\text { Absence of } \\
\text { HBIQ }\end{array}$ & $\begin{array}{c}\text { Atomic } \\
\text { percentage } \\
(\%) \\
\text { Presence of } \\
\text { HBIQ }\end{array}$ \\
\hline C & 3.47 & 6.24 \\
\hline $\mathbf{N}$ & 0.23 & 0.35 \\
\hline $\mathbf{O}$ & 17.85 & 5.38 \\
\hline $\mathbf{S i}$ & 0.61 & 0.62 \\
\hline $\mathbf{S}$ & 0.34 & - \\
\hline Mn & 1.12 & - \\
\hline $\mathrm{Fe}$ & 76.73 & 87.41 \\
\hline
\end{tabular}

Fig. 8 SEM images of MS material a immersed in 1 M SA b immersed in 1 MSA+HBIQ. AFM image of MS material c immersed in $1 \mathrm{M}$ SA d immersed in $1 \mathrm{M}$ SA+HBIQ. The table

The EDX profile of MS surface after its immersion in $1 \mathrm{M}$ SA solution along with atomic percentage of the elements in the absence and presence of HBIQ is depicted in Fig. 8e and $\mathrm{f}$ correspondingly. From the data table it can be observed that for the corroded sample the percentage of sulfur, nitrogen and oxygen is $0.23,0.35$ and $7.85 \%$, respectively, which confirms the adsorption of sulfamate ions $\left(\mathrm{H}_{2} \mathrm{NSO}_{3}{ }^{-}\right)$ from the acid solution on to the metal surface. Further, the increase in the carbon percentage (3.47-6.24) and decrease in the oxygen percentage (17.85-5.38) in the presence of HBIQ endorse its adsorption on to the MS surface. represents surface roughness values in the absence and presence of HBIQ. EDX spectrum of MS surface $\mathbf{e}$ immersed in $1 \mathrm{M} \mathrm{SA} \mathbf{f}$ immersed in $1 \mathrm{M} \mathrm{SA}+\mathrm{HBIQ}$

\section{Conclusions}

A naphthalimide derivative HBIQ was prepared by easy synthetic protocol from acenaphthene and following inferences are drawn from the various investigations performed to study its corrosion inhibition capability.

- Potentiodynamic studies validated HBIQ as a mixedtype corrosion inhibitor for mild steel corrosion in $1 \mathrm{M}$ Sulfamic acid, and exhibited a concentration-dependent rise in the inhibition efficiency.

- HBIQ molecules adsorbed on to the metal surface, obeying Langmuir isotherm to form a protective film that hinders the metal corrosion. 
- Activation energy and thermodynamic parameters established physisorption of HBIQ on metal surface.

- SEM and AFM images supported by EDX analyses demonstrated the protective film formation of HBIQ on MS surface which acts as a barrier to the sulfamic acid medium.

- Theoretical studies supplemented the experimental data and showed that the high HOMO and low LUMO values enabled adsorption of HBIQ on to the metal and the $\mathrm{N}$ and $\mathrm{O}$ atoms and the $\pi$-electron centers aid in strong interactions with $\mathrm{Fe}$ to bind to the metal surface.

Hence, the naphthalimide derivative HBIQ can be potential inhibitor to combat the corrosion of MS in sulfamic acid environment.

Supplementary Information The online version contains supplementary material available at https://doi.org/10.1007/s11696-021-01608-9.

Acknowledgements The authors are grateful to Department of Chemistry, Manipal Institute of Technology, Manipal Academy of Higher Education for providing Laboratory Facility.

Funding Open access funding provided by Manipal Academy of Higher Education, Manipal.

\section{Declarations}

Conflicts of interest The authors do not have any conflict of interest.

Open Access This article is licensed under a Creative Commons Attribution 4.0 International License, which permits use, sharing, adaptation, distribution and reproduction in any medium or format, as long as you give appropriate credit to the original author(s) and the source, provide a link to the Creative Commons licence, and indicate if changes were made. The images or other third party material in this article are included in the article's Creative Commons licence, unless indicated otherwise in a credit line to the material. If material is not included in the article's Creative Commons licence and your intended use is not permitted by statutory regulation or exceeds the permitted use, you will need to obtain permission directly from the copyright holder. To view a copy of this licence, visit http://creativecommons.org/licenses/by/4.0/.

\section{References}

Abd El Rehim SS, Hassan HH, Amin MA (2001) Corrosion inhibition of aluminum by 1,1(lauryl amido)propyl ammonium chloride in $\mathrm{HCl}$ solution. Mater Chem Phys 70:64-72

Abd El Rehim SS, Abdel-Fatah HTM, El-Sehiety HEE (2016) Inhibitive action of cystine on the corrosion of low alloy steel ASTM A213 grade T22 in sulfamic acid solutions. Arab J Chem 9:388394. https://doi.org/10.1016/j.arabjc.2011.05.003

Abdel-Fatah HTM, Rashwan SAM, Abd El Wahaab SM, Hassan AAM (2016) Effect of tryptophan on the corrosion behavior of low alloy steel in sulfamic acid. Arab J Chem 9:1069-1076. https://doi.org/ 10.1016/j.arabjc.2011.11.012

Abdel-Fatah HTM, Kamel MM, Hassan AAM, Rashwan SAM, Abd El Wahaab SM, El-Sehiety HEE (2017) Adsorption and inhibitive properties of tryptophan on low alloy steel corrosion in acidic media. Arab J Chem 10:1164-1171

Abdallah YM, Shalabi K, Bayoumy NM (2018) Eco-friendly synthesis, biological activity and evaluation of some new pyridopyrimidinone derivatives as corrosion inhibitors for API 5L X52 carbon steel in 5\% sulfamic acid medium. J Mol Struct 1171:658-671. https://doi.org/10.1016/j.molstruc.2018.06.045

Ahmed MH, Al-Amiery A, Al-Majedy Y, Kadhum A, Mohamad A, Gaaz T (2018) Synthesis and characterization of a novel organic corrosion inhibitor for mild steel in $1 \mathrm{M}$ hydrochloric acid. Results Phys 8:728-733

Ahmed S, Ali WB, Khadom AA (2019) Synthesis and investigations of heterocyclic compounds as corrosion inhibitors for mild steel in hydrochloric acid. Int J Ind Chem 10:159-173

Al-Azawi K, Al-Baghdadi I, Salman TA, Issa HA, Al-Amiery AA, Sumer Gaaz T, Kadhum AH (2018) Experimental and quantum chemical simulations on the corrosion inhibition of mild steel by 3-((5-(3,5-dinitrophenyl)-1,3,4-thiadiazol-2-yl)imino)indolin2-one. Results Phys 9:278-283

Amin MA, Abd El-Rehim SS, El-Sherbini EEF, Bayyomi RS (2007) The inhibition of low carbon steel corrosion in hydrochloric acid solutions by succinic acid: part I. Weight loss, polarization, EIS, PZC EDX and SEM studies. Electrochim Acta 52:3588-3600

Aoufir YEL, Bakri YEL, Lgaz H, Zarrouk A, Salghi R, Warad I, Ramli Y, Guenbour A, Essassi EM, Oudda H (2017) Understanding the adsorption of benzimidazole derivative as corrosion inhibitor for carbon steel in $1 \mathrm{M} \mathrm{HCl}$ : experimental and theoretical studies. J Mater Environ Sci 8:3290-3302

Berque-Bestel I, Soulier JL, Giner M, Rivail L, Langlois M, Sicsic S (2003) Synthesis and characterization of the first fluorescent antagonists for human 5-HT4 receptors. J Med Chem 46:26062620. https://doi.org/10.1021/jm0307887

Bhuvneshvari TK, Jeyaprabha C, Arulmathi P (2020) Corrosion inhibition of mild steel in hydrochloric acid by leaves extract of tephrosiapurpurea. J Adhes Sci Technol 34:2424-2447. https://doi.org/ 10.1080/01694243.2020.1766395

Boudjellal F, Ouici HB, Guendouzi A, Benali O, Sehmi A (2020) Experimental and theoretical approach to the corrosion inhibition of mild steel in acid medium by a newly synthesized pyrazolecarbothioamide heterocycle. J Mol Struct 1199:127051

Chaitha BP, Rao P (2017) Electrochemical and adsorption studies for the corrosion control of 6061 aluminium alloy using eco-friendly inhibitor. Surf Eng Appl Electrochem 53:551-559

Clark RD, Weinhardt KK, Berger J, Lee CH, Leung E, Wong EHF, Smith WL, Eglen RM (1993) N-(quinuclidin-3-YL)-1,8-naphthalimides with 5-HT3 receptor antagonist and 5-HT4 receptor agonist properties. Bioorganic Med Chem Lett 3:1375-1378. https:// doi.org/10.1016/S0960-894X(00)80352-2

Dorlars A, Schellhammer CW, Schroeder J (1975) Heterocycles as structural units in new optical brighteners. Intl Ed Engl 14:665679. https://doi.org/10.1002/anie.197506651

Duke RM, Veale EB, Pfeffer FM, Krugerc PE, Gunnlaugsson T (2010) Colorimetric and fluorescent anion sensors: an overview of recent developments in the use of 1,8-naphthalimide-based chemosensors. Chem Soc Rev 39:3936-3953. https://doi.org/10.1039/ B910560N

El-Haddad MN, Elattar KM (2015) Synthesis, characterization and inhibition effect of new antipyrinyl derivatives on mild steel corrosion in acidic solution. Int J Ind Chem 6:105-117

Fouda AS, Elmorsi MA, Fayed T, EL Said M (2014) Oxazole derivatives as corrosion inhibitors for $316 \mathrm{~L}$ stainless steel in sulfamic acid solutions. Res J Chem Sci 4:62-74

Fouda AS, Abd El-Maksoud SA, Zoromba MS, Ibrahim AR (2017) Corrosion inhibition and thermodynamic activation parameters of Myrtuscommunis extract on mild steel in sulfamic acid medium. Int J Corros Scale Inhib 6:428-448 
Fouda AS, Ibrahim AR (2018) Aqueous extract of juniperus as a green corrosion inhibitor for mild steel (MS) in sulfamic acid $\left(\mathrm{NH}_{2} \mathrm{SO}_{3} \mathrm{H}\right)$ solutions. Prot Met Phys Chem Surf 54:1194-1203

Gao G, Liang C (2007) Electrochemical and DFT studies of $\beta$-aminoalcohols as corrosion inhibitors for brass. Electrochim Acta 52:4554-4559

Huang W, Chen B, Zhang G (2019) Persistent room-temperature radicals from anionic naphthalimides: spin pairing and supramolecular chemistry. Chem Eur J 25:12497-12501

Kamal A, Reddy BSN, Reddy GSK, Ramesh G (2002) Design and synthesis of C-8 linked pyrrolobenzodiazepine-naphthalimide hybrids as anti-tumour agents. Bioorganic Med Chem Lett 12:1933-1935. https://doi.org/10.1016/s0960-894x(02)00326-8

Khaled KF (2008) Application of electrochemical frequency modulation for monitoring corrosion and corrosion inhibition of iron by some indole derivatives in molar hydrochloric acid. Mater Chem Phys 112:290-300

Kokalj A (2010) Is the analysis of molecular electronic structure of corrosion inhibitors sufficient to predict the trend of their inhibition performance. Electrochim Acta 56:745-755

Kovačević N, Kokalj A (2011) Analysis of molecular electronic structure of imidazole-and benzimidazole-based inhibitors: a simple recipe for qualitative estimation of chemical hardness. Corros Sci 53:909-921

Kumari P, Shetty P, Rao S (2014) Corrosion inhibition effect of 4-Hydroxy-N'-[(E)-(1H-indole-2-ylmethylidene)] benzohydrazide on mild steel in hydrochloric acid solution. Int J Corros 256424:111. https://doi.org/10.1155/2014/256424

Kumari P, Shetty P, Rao S (2015) Corrosion protection properties of 4-hydroxy-N'-[(1E, 2E)-3-Phenylprop-2-en-1-ylidene] Benzohydrazide on mild steel in hydrochloric acid medium. Prot Met Phys Chem Surf 51:1034-1042

Kumari P, Shetty P, Rao S (2017a) Electrochemical measurements for the corrosion inhibition of mild steel in $1 \mathrm{M}$ hydrochloric acid by using an aromatic hydrazide derivative. Arab J Chem 10:653-663

Kumari P, Shetty P, Rao SA, Sunil D (2017b) Inhibition behaviour of 2-[(2-Methyquinoline-8-yl)nOxy] acetohydrazide corrosion of mild steel in hydrochloric acid solution. Trans Indian Inst Met 70:1139-1150

Kumari P, Shetty N, Sunil D (2020a) Effect of cysteine as environmentally friendly inhibitor on AA6061-T6 corrosion in $0.5 \mathrm{M} \mathrm{HCl}$ : electrochemical and surface studies. Surf Eng Appl Electrochem 56:624-634

Kumari P, Shetty P, Rao S, Sunil D, Vishwanath T (2020b) Synthesis, characterization and anticorrosion behaviour of a novel hydrazide derivative on mild steel in hydrochloric acid medium. Bull Mater Sci 43:46

Lebrini M, Roos C, Vezin H, Robert F (2011) Electrochemical and theoretical studies of adsorption of some indole derivatives C38 steel/sulfuric acid interface as corrosion inhibitors. Int J Electrochem Sci 6:3844-3857

Li W, He Q, Pei C, Hou B (2007) Experimental and theoretical investigation of the adsorption behaviour of new triazole derivatives as inhibitors for mild steel corrosion in acid media. Electrochim Acta 52:6386-6394

Martinez S, Stern I (2002) Thermodynamic characterization of metal dissolution and inhibitor adsorption processes in the low carbon steel/mimosa tannin/sulfuric acid system. Appl Surf Sci 199:83-89

Mistry BM, Jauhari S (2013) Synthesis and evaluation of some quinoline Schiff bases as a corrosion inhibitor for mild steel in $1 \mathrm{~N} \mathrm{HCl}$. Res Chem Intermed 39:1049-1068

Mistry BM, Jauhari S (2015) Studies on the inhibitive effect of (Z)4-chloro-N-((2-chloroquinolin-3-yl)methylene)aniline schiff base on the corrosion of mild steel in $1 \mathrm{~N} \mathrm{HCl}$ solution. Res Chem Intermed 41:6289-6307
Morad MS (2008) Corrosion inhibition of mild steel in sulfamic acid solution by s-containing amino acids. J Appl Electrochem 38:1509-1518

Motamdi M, Tehrani-Bagha AR, Mahdavian M (2011) A comparative study on the electrochemical behaviour of mild steel in sulfamic acid solution in the present of monomeric and Gemini surfactants. Electrochim Acta 58:488-496. https://doi.org/10.1016/j.electacta. 2011.09.079

Motamedi M, Tehrani-Bagha AR, Mahdavian M (2013) Effect of aging time on corrosion inhibition of cationic surfactant on mild steel in sulfamic acid cleaning solution. Corros Sci 70:46-54

Motamedi M, Tehrani-Bagha AR, Mahdavian M (2014) The effect of cationic surfactants in acid cleaning solutions on protective performance and adhesion strength of the subsequent polyurethane coating. Prog Org Coat 77:712-718

Muth M, Hoerr V, Glaser M, Ponte-Sucre A, Moll H, Stich A, Holzgrabe U (2007) Antitrypanosomal activity of quaternary naphthalimide derivatives. Bioorganic Med Chem Lett 17:1590 1593. https://doi.org/10.1016/j.bmcl.2006.12.088

Obot IB, Macdonald DD, Gasem ZM (2015) Density functional theory (DFT) as a powerful tool for designing new organic corrosion inhibitors: part 1: an overview. Corros Sci 99:1-30

Pearson RG (1986) Absolute electronegativity and hardness correlated with molecular orbital theory. Proc Natl Acad Sci USA 83:8440-8441

Pinto GM, Nayak J, Shetty AN (2011) Corrosion inhibition of 6061 Al-15 vol. pct. $\mathrm{SiC}(\mathrm{p})$ composite and its base alloy in a mixture of sulphuric acid and hydrochloric acid by 4-(N, N-dimethyl amino) benzaldehyde thiosemicarbazone. Mater Chem Phys 125:628640. https://doi.org/10.1016/j.matchemphys.2010.10.006

Popova A, Sokolova E, Raicheva S, Christov M (2003) AC and DC study of the temperature effect on mild steel corrosion in acid media in the presence of benzimidazole derivatives. Corros Sci 45:33-58

Quraishi MA, Jamal D (2001) Influence of laisen-schmit products on Corrosion of mild steel in sulphamic acid. Bull Electrochem 17:273-276

Rbaa M, Galai M, Aboualem AS, Lakhrissi B, EbnTouhami M, Warad I, Zarrouk A (2020) Synthetic, spectroscopic characterization, empirical and theoretical investigations on the corrosion inhibition characteristics of mild steel in molar hydrochloric acid by three novel 8-hydroxyquinoline derivatives. Ionics 26:503-522

Saliyan VR, Adhikari AV (2008) Quinolin-5-ylmethylene-3-\{[8(trifluoromethyl)quinolin-4-yl]thio $\}$ propanohydrazide as an effective inhibitor of mild steel corrosion in $\mathrm{HCl}$ solution. Corros Sci 50:55-61

Sastri VS, Perumareddi JR (1997) Molecular orbital theoretical studies of some organic corrosion inhibitors. Corrosion 53:617-622. https://doi.org/10.5006/1.3290294

Shukla SK, Ebenso EE (2011) Corrosion inhibition, adsorption behavior and thermodynamic properties of streptomycin on mild steel in hydrochloric acid medium. Int J Electrochem Sci 6:3277-3291

Sneha K, Sunil D, Kumari P, Shetty P (2020) Investigation of anticorrosive property of Carbazolecarbaldehyde azine on mild steel using electrochemical, morphological and theoretical studies. J Bio Tribo Corros 6, Article number: 136. https://doi.org/10.1007/ s40735-020-00433-z

Wang H, Wang X, Wang H, Wang L, Liu A (2007) DFT study of new bipyrazole derivatives and their potential activity as corrosion inhibitors. J Mol Model 13:147-153. https://doi.org/10.1007/ s00894-006-0135-x

Wang L, Shinohara T, Zhang B (2010) Influence of chloride, sulfate and bicarbonate anions on the corrosion behavior of AZ31 magnesium alloy. J Alloys Compd 496:500-507. https://doi.org/10. 1016/j.jallcom.2010.02.088 
Wolfbeis OS (2005) Materials for fluorescence-based optical chemical sensors. J Mater Chem 15:2657-2669

Yadav M, Gope L, Sarkar TK (2016) Synthesized amino acid compounds as eco-friendly corrosion inhibitors for mild steel in hydrochloric acid solution: electrochemical and quantum studies. Res Chem Intermed 42:2641-2660

$\mathrm{Xu}$ Z, Yoon J, Spring DR (2010) A selective and ratiometric $\mathrm{Cu}^{2+}$ fluorescent probe based on naphthalimide excimer-monomer switching. Chem Commun 46:2563-2565. https://doi.org/10. 1039/C000441C

Publisher's Note Springer Nature remains neutral with regard to jurisdictional claims in published maps and institutional affiliations. 